\title{
Factors Influencing the Choice of Hospital after Primary Total Hip and Knee Replacement Surgeries
}

\section{Tom Schaal ${ }^{1 *}$, Schoenfelder $\mathbf{T}^{1}$, Klewer $\mathbf{J}^{2}$ and Kugler $\mathbf{J}^{1}$}

${ }^{1}$ Department of Public Health, Dresden Medical School, University of Dresden, Germany

${ }^{2}$ Department of Public Health and Health Care Management, University of Applied Sciences Zwickau, Dr.-Friedrichs-Ring 2A, 08056 Zwickau, Germany

\begin{abstract}
Objective: Studies on the overall satisfaction of patients after surgery of primary total hip or knee replacement (THR or TKR) rarely consider factors that influence the choice of a hospital separately, although the need for such studies is sufficiently justified. The aim of this study was to weigh patient expectations in the future choice of a hospital
\end{abstract} and to study the differences between THR and TKR patients.

Methods: A written survey was conducted of 827 THR and 868 TKR patients at 43 hospitals, after they were discharged. Socio-demographic data were evaluated together with 13 hospital, treatment and service-related criteria, using a six-point scale.

Results: Survey participants considered the quality of the treatment received as the most important factor in their choice of hospital and the recommendations of the hospital in a hospital guide as the least significant factor. On average (grouped median), the relevance of all items surveyed was ranked from less important to extremely important. The responses from THR and TKR patients showed differences only when they were asked to provide information about the planned treatment.

Conclusion: The significant differences between the two treatment groups had no practical relevance based on the underlying medians (5.69 vs. 5.75). Consequently, there were no differences between THR and TKR patients in weighting the different criteria with regard to selecting a hospital. The recommendations indicated can be applied equally to both groups of patients. For example, if patients were to avail of hospital guides or online resources more frequently, patients could choose among hospitals based on the quality of treatment achieved. Therefore, it is recommended that more patients be made aware of this possibility.

Keywords: Hip replacement; Knee replacement; Choice of hospital; Patient expectations; Surgery

\section{Objectives}

Osteoarthritis is the world's most common form of joint disease and the eleventh most common cause of disabilities [1]. Primary total hip and knee replacements (THR or TKR) as cost-effective surgical interventions will experience even greater demand in the near future as the treatment of choice for osteoarthritis, because these procedures, besides relieving the pain, improve the quality of life, mobility and the ambulatory status (walking ability) of those affected [2-4].

A few studies on patient satisfaction, which were designed to improve on the knowledge of healthcare providers, have considered the significance of patient expectations and have revealed that the conceptual questions about patients' expectations of healthcare providers remain differentiated by the outcome of the treatment [58]. Various studies have shown that reports published of treatment quality have been considered by patients in their choice, and that higher expectations are associated with better qualitative results $[9,10]$. Ketelaar et al. collected the hospital-related factors behind the selection of hospitals, and found that their reputation and their distance from the patient's home were the most significant ones [11]. Webb and Lloyd concluded that patient expectations can influence physicians in their decisions [12]. Differences in physician and patient expectations causes dissatisfaction that can affect patient health and any associated costs $[13,14]$. Since patient expectations are an important indicator of healthcare quality and cost, they have been of increasing interest for health professionals and policy makers $[15,16]$.

The current study was conducted to collect and compare data on patient expectations of future hospitalizations, after their primary THR or TKR.

\section{Methods}

This cross-sectional study included randomly selected patients from 43 hospitals within one federal state in Germany, who had received a THR or TKR between 2010 and 2011. It was based on a selfadministered questionnaire, which was completed after the hospital stay. The survey was aimed at patients of five statutory health insurance providers, which together have a market share of $78 \%$ of the total population, in order to ensure the use of a uniform questionnaire and to exclude any deliberate selection of patients by the hospitals. A cover letter informed patients about the purpose of the survey and informed them that returning the questionnaire and thereby participating in the study was voluntary and anonymous.

A total of 6,812 postage-paid questionnaires were mailed to THR patients and 7,108 were sent to TKR patients, of which 827 and 868 , respectively, were received back and were analyzed.

In addition to socio-demographic data, the surveys asked

*Corresponding author: Tom Schaal, MPH, Department of Public Health, Dresden Medical School, University of Dresden, Loescherstrasse 18, 01309 Dresden, Germany, Tel: +(49) 152549282 51; Fax: +(49) 351317 7459; E-mail: tom.schaal@gmx.de

Received: July 25, 2016; Accepted: September 13, 2016; Published: September 20, 2016

Citation: Schaal T, Schoenfelder T, Klewer J, Kugler J (2016) Factors Influencing the Choice of Hospital after Primary Total Hip and Knee Replacement Surgeries. $J$ Pat Care 2: 120. doi: 10.4172/2573-4598.1000120

Copyright: $\odot 2016$ Schaal T, et al. This is an open-access article distributed under the terms of the Creative Commons Attribution License, which permits unrestricted use, distribution, and reproduction in any medium, provided the original author and source are credited. 
respondents to answer thirteen questions about what would be particularly important to them in choosing a future hospital stay, by rating different elements on a six-point scale (extremely important, very important, important, less important, rather unimportant, not at all important) [1-6]. Results indicated a left skewed distribution for better analysis and that the expectations reflected the quality and explanation of treatment, hospital recommendations, hospital characteristics, and service aspects.

The descriptive statistics and frequencies were calculated. The nonparametric Mann-Whitney $U$ test was used to represent the differences between the THR and TKR patient groups. The significance level for the entire study was $\mathrm{p}<0.05$. The data analysis was performed using the SPSS version 20.0 software (SPSS Inc., Chicago, IL, USA).

\section{Results}

The studied population included 1,060 female and 610 male participants, of which $284(34.8 \%)$ men and 532 (65.2\%) women had received a THR and 326 (38.2\%) men and 528 (61.8\%) women had received a TKR (Figure 1). Of these, 25 respondents failed to respond to the question about gender. Eight patients between the ages of 21 and 50 received THR (1\%), and seventeen patients in that same age group received a TKR $(2 \%)$. Of the cohort between 51 and 60 of age, 86 members had a THR (10.4\% of the total respondents), and 84 had a TKR (9.7\%). Of those between 61 and 70 of age, 240 (29.1\%) were recipients of a THR and 256 (29.6\%) were recipients of a TKR. The largest group of respondents was that between 71 and 80 years of age, with 392 (47.6\%) having had a THR and 410 (47.4\%) having had a TKR. Above the age of 80 , there were 98 patients in each of the THR and TKR recipient groups (11.9\% and $11.3 \%$, respectively). Six respondents did not provide any age information.

For the respondents, the highest priority for future hospital care after primary THR or TKR was the quality of treatment (Figure 2). Only

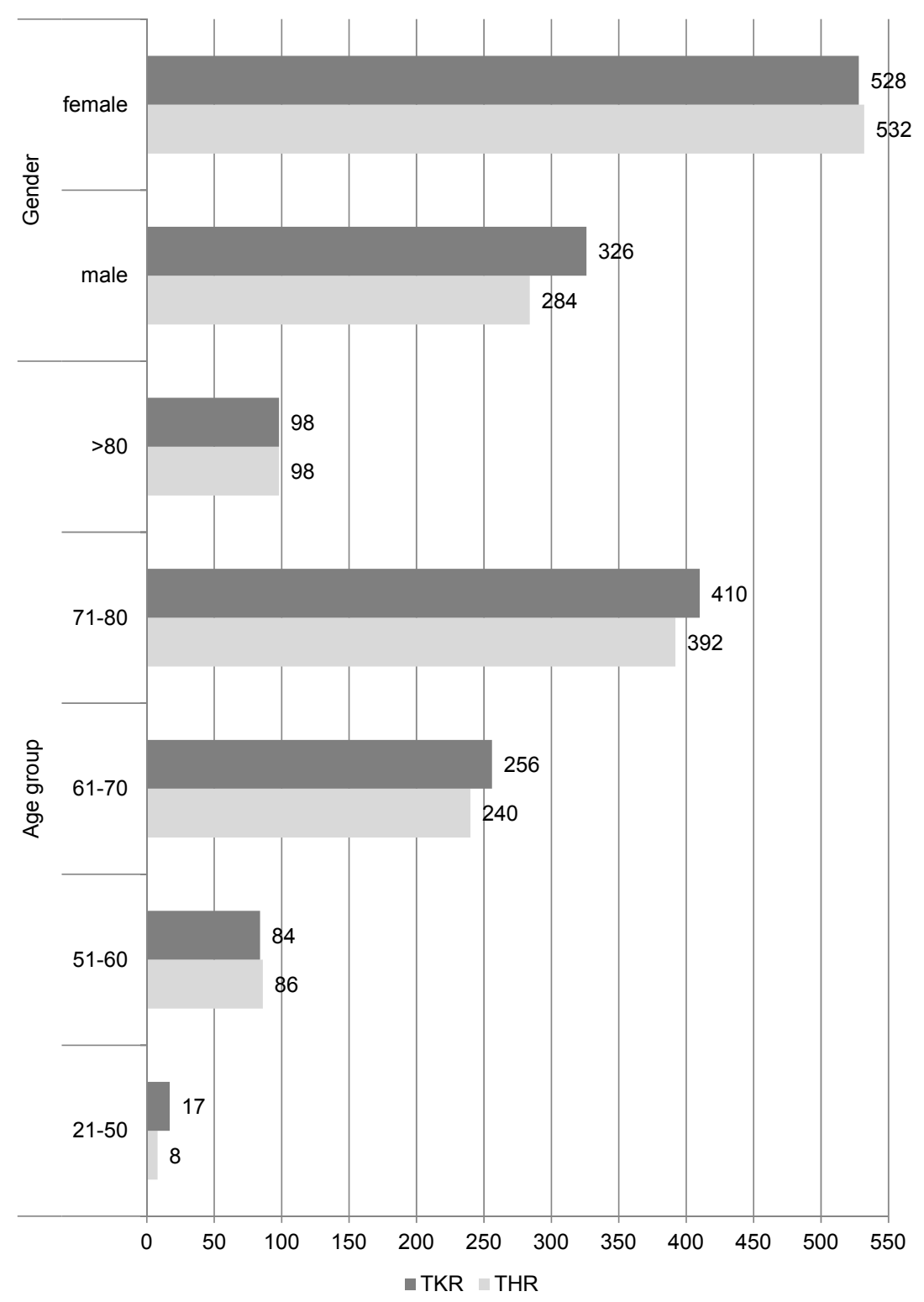

Figure 1: Distribution of gender and age. 


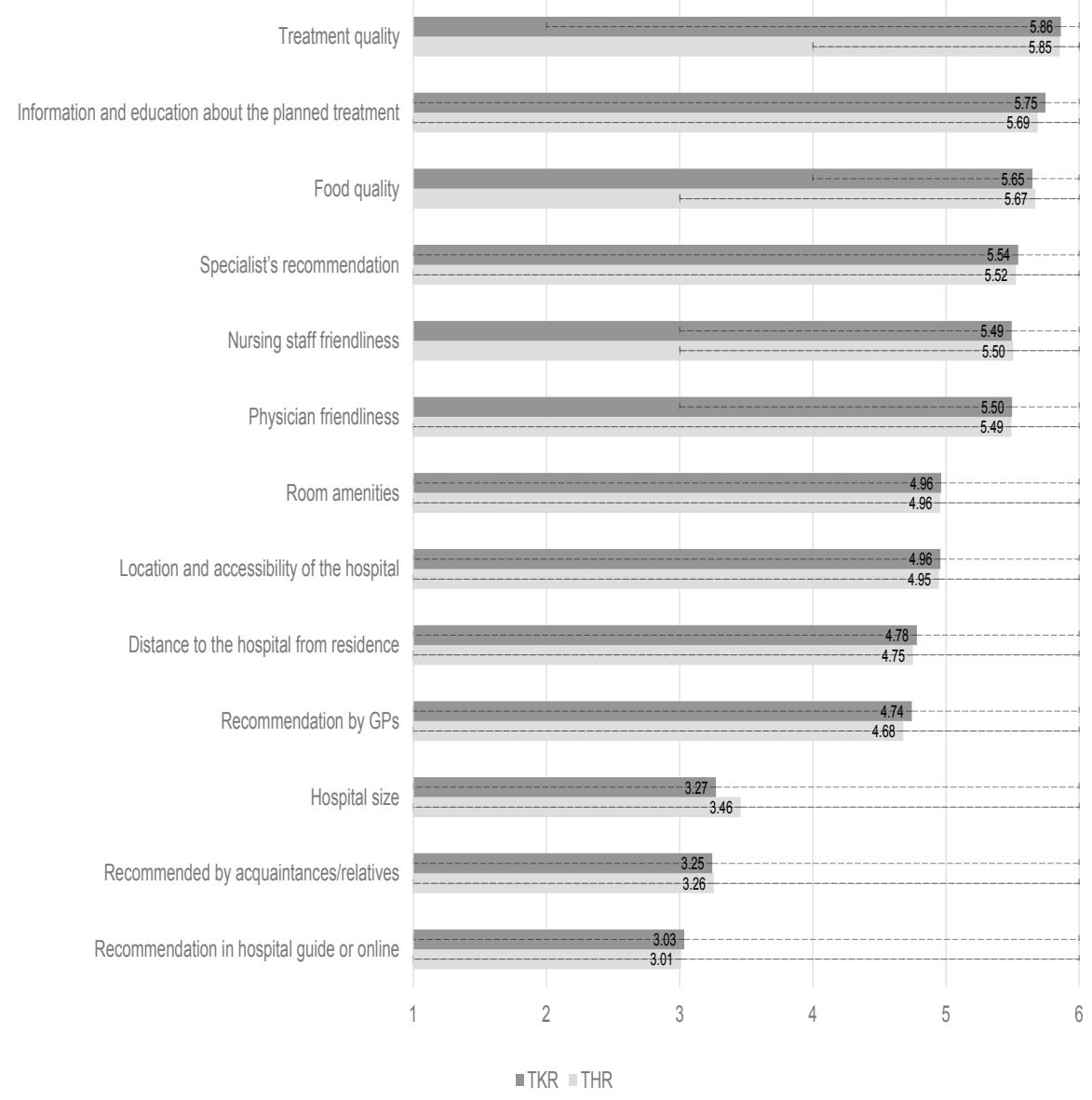

Figure 2: Distribution of patient expectations after THR and TKR (grouped median [min., max.]).

one TKR patient marked treatment quality as "rather unimportant", while the lowest rating given by THR patients for the quality of treatment was "important" ( $\mathrm{n}=6)$. In contrast, the quality of food came into third place in terms of importance, with TKR patients marking it as least "important" $(n=36)$. With the exception of the two questions about the friendliness of physicians and nursing staff, the ranking of expectations among both groups was equivalent. The grouped median for physician friendliness was slightly higher for the TKR patients, as compared to that for nursing staff friendliness; a difference not found with the THR patients. No patient marked nursing staff friendliness as "rather unimportant" or "not at all important", while one THR patient did mark physician friendliness as "not at all important". Both patient groups attached the least importance to hospital size, recommendations from friends and relatives and recommendations in published hospital guides or websites. Regarding the question that was exclusively about information and education about the planned treatment, the bivariate analysis revealed a significant difference $(p=0.013)$ between the THR and TKR patient groups. Because the remaining questions could be adequately protected against random responses, no statistically significant differences between the two patient groups were determined.

\section{Discussion}

This multi-center study surveyed a sample of 827 THR and 868 TKR patients from 43 German hospitals. Despite significant differences in the THR and TKR patients' responses to the question about information and education about the proposed treatment, the proximity of both medians and the same ranking indicates no practical relevance for the differences between the two groups of patients. The results can be used across hospitals by healthcare policymakers for better understanding patient expectations and for improving patient-centered interactions through measures targeted for THR and TKR patients alike.

The limited significance of hospital recommendations in hospital guides or websites supports the results of Fung et al. [17] and Doering and Maarse [18], which state that only $4 \%$ to $14 \%$ of patients include comparable quality indicators in their decision. Since it was not a lack of interest nor any lack of understanding that explains why patients make so little use of publicly available qualitative information, but that it was instead an unawareness of its relevance [19], patients should be made more aware of the options for selecting providers based on published quality indicators [11]. These include thorough information about the quality of treatment, which received the highest priority among the respondents and could contribute to improving their levels of future satisfaction [11]. The respondents' second most important criterion was being fully informed about the planned treatment, which can be seen as an incentive to provide even better consulting about the outcomes that can be expected from upcoming operations. There are frequent misconceptions about the degree to which functional limitations can be overcome, which are associated with dissatisfaction and indicate a lack of education $[20,21]$. Various studies have shown that the quality of food is treated as a surrogate indicator of patient satisfaction with the medical treatment, because patients are in a position to judge it qualitatively $[22,23]$. In this study, this surrogate indicator can be 
seen as a potential reason for the high importance attributed to the quality of the food when choosing hospitals. General practitioner (GP) recommendations were of secondary importance for respondents, confirming the results of Webb and Lloyd [12], who found that these were less important, and that other factors were more likely to affect the choice of a hospital. Contrary to the recommendations of Jung et al. [24], specialists should be more informed than GPs about patient expectations, include these in their decisions [12], and provide patients with targeted advice on a choice of hospital. In contrast to the results of Ketelaar et al., the distance to the hospital was less important and was in the lower half of the weighted factors, along with the hospital size [11].

\section{Limitations}

Interpreting these results is subject to several limitations. The first is that no information was available about those who chose not to participate. Emberton and Black [25] and Polk et al. [26] found that the distortions due to non-respondents in the results of postsurgery satisfaction surveys are negligible. Since the influence of nonparticipants could not be controlled and the net rate of return was $12.1 \%$ and $12.2 \%$, respectively, potential response bias and its resulting limitations to the study results cannot be excluded [27]. Second, while the sample of patients from 43 hospitals does approximate the hospital structure of a region of Germany, the ability to generalize the results to other regions and countries still needs to be clarified [28]. Third, the present study cannot claim to be exhaustive, due to a number of intangible factors that can influence the choice of a hospital [29].

\section{Conclusion}

When considered apart from the treatment outcome, the results of the study allow a differentiated consideration of patient expectations when choosing a hospital, which can help to improve the present state of knowledge within the healthcare industry. The highest importance was attached to the variables that can be influenced by the health professions or management; those of fixed parameters, such as hospital size and distance, were considered less important. If set up as an intervention study, future studies can build on the results by testing the effectiveness of the measures suggested and enhances the current research regarding the causal relationships among patient expectations when choosing a hospital as well as their overall satisfaction.

\section{Acknowledgement}

The authors thank the patients and the health professionals who contributed to this study.

\section{Conflict of Interests}

All authors declare that they have no conflict of interests. The study was carried out without funding

\section{References}

1. Palazzo C, Nguyen C, Lefevre-Colau MM, Rannou F, Poiraudeau S (2016) Risk factors and burden of osteoarthritis. Ann Phys Rehabil Med 59: 134-138.

2. Learmonth ID, Young C, Roraback C (2007) The operation of the century: Total hip replacement. Lancet 370: 1508-1519.

3. Pivec R, Johnson AJ, Mears SC, Mont MA (2012) Hip arthroplasty. Lancet 380: 1768-1777.

4. Carr AJ, Robertsson O, Graves S, Price AJ, Arden NA, et al. (2012) Knee replacement. Lancet 379: 1331-1340.

5. Crow R, Gage H, Hampson S, Hart J, Kimber A, et al. (2002) The measurement of satisfaction with healthcare: Implications for practice from a systematic review of the literature. Health Technol Assess 6: 32

6. Schulze A, Scharf HP (2013) Satisfaction after total knee arthroplasty Comparison of 1990-1999 with 2000-2012. Orthopade 42: 858-865.
7. Abedi G, Rostami F, Ziaee M, Siamian H, Nadi A (2015) Patient's perception and expectations of the quality of outpatient services of Imam Khomeini hospital in Sari City. Mater Sociomed 27: 272-275.

8. Haanstra TM, Berg T, Ostelo RW, Poolam RW, Jansma IP, et al. (2012) Systematic review: Do patient expectations influence treatment outcomes in total knee and total hip arthroplasty? Health Qual Life Outcomes 10: 152.

9. Varkevisser M, Geest SA, Schut FT (2012) Do patients choose hospitals with high quality ratings? Empirical evidence from the market for angioplasty in the Netherlands. J Health E 31: 371-378.

10. Howard D (2006) Quality and consumer choice in healthcare: Evidence from kidney transplantation. Top Econ Anal Policy 5: 1349.

11. Ketelaar NA, Faber MJ, Braspenning JC, Westert GP (2014) Patients' expectations of variation in quality of care relates to their search for comparative performance information. BMC Health Serv Res 14: 617.

12. Webb S, Lloyd M (1994) Prescribing and referral in general practice: A study of patients' expectations and doctors' actions. Br J Gen Pract 44: 165-169.

13. Mann C, Gooberman-Hill R (2011) Health care provision for osteoarthritis: Concordance between what patients would like and what health professionals think they should have. Arthritis Care Res 63: 963-972.

14. Safran DG, Montgomery JE, Chang H, Murphy J, Rogers WH (2001) Switching doctors: Predictors of voluntary disenrollment from a primary physician's practice. J Fam Pract 50: 130-136.

15. Richards T (1999) Patients' priorities. BMJ 318: 277.

16. Porter ME (2010) What is value in health care? N Engl J Med 363: 2477-2481

17. Fung CH, Lim YW, Mattke S, Damberg C, Shekelle PG (2008) Systematic review: The evidence that publishing patient care performance data improves quality of care. Ann Intern Med 148: 111-123.

18. Doering N, Maarse H (2015) The use of publicly available quality information when choosing a hospital or health-care provider: The role of the GP. Health Expect 18: 2174-2182.

19. Goodell S, Harris K (2008) Choosing a health care provider: The role of quality information. Robert Wood Johnson Foundation 14: 1-4.

20. Tung YC, Chang GM (2009) Patient satisfaction with and recommendation of primary care provider: Associations of perceived quality and patient education. Int J Qual Health Care 21: 206-213.

21. Kliot T, Zygourakis CC, Imershein S, Lau C, Kliot M (2015) The impact of a patient education bundle on neurosurgery patient satisfaction. Surg Neurol Int 16: $567-572$

22. Otani K, Kurz RS, Harris L, Byrne FD (2005) Managing primary care using patient satisfaction measures. J Healthc Manag 50: 311-325.

23. Dall'Oglio I, Nicolò R, Di Ciommo V, Bianchi N, Ciliento G, et al. (2015) A systematic review of hospital food service patient satisfaction studies. J Acad Nutr Diet 115: 567-584.

24. Jung HP, Wensing M, Grol R (1997) What makes a good general practitioner Do patients and doctors have different views? Br J Gen Pract 47: 805-809.

25. Emberton M, Black N (1995) Impact of non-response and of late-response by patients in a multi-centre surgical outcome audit. Int J Qual Health Care 7: 47-55.

26. Polk A, Rasmussen JV, Brorson S, Olsen BS (2013) Reliability of patient-reported functional outcome in a joint replacement registry. Acta Orthopaedica 84: 12-17.

27. Bamm EL, Rosenbaum P, Stratford P (2010) Validation of the measure of processes of care for adults: A measure of client-centred care. Int J Qual Health Care 22: 302-309.

28. Klit J, Jacobsen S, Rosenlund S, Sonne-Holm S, Troelsen A (2013) Total knee arthroplasty in younger patients evaluated by alternative outcome measures. Arthroplasty 29: 912-917

29. Nekoei-Moghadam M, Amiresmaili M (2011) Hospital services quality assessment: Hospitals of Kerman University of Medical Sciences, as a tangible example of a developing country. Int J Health Care Qual Assu 24: 57-66. 